\title{
Design of a System for Monitoring Reliability of Structures and Constructions in Civil Engineering
}

\author{
doi:10.3991/ijep.v1i2.1634 \\ T.S. Igić and N.Ž. Veljković \\ University of Niš, Niš, Serbia
}

\begin{abstract}
Monitoring of civil engineering structures and constructions requires techniques which can produce high precision and accuracy, reliable measurements and fast processing speed. The development of information and communication systems as well as of microprocessor controllers has enabled a creation of monitoring systems that can be used for tracking reliability of structures and constructions in civil engineering, with described key features. This paper describes in detail the architecture of the Civil Engineering Structures Reliability Monitoring (CERM) system. The system has been designed for the purposes of the Technical Mechanics and Theory of Constructions Department at the Faculty of Civil Engineering and Architecture, University of Nis. Unlike general commercial monitoring systems, the CERM system has been specially designed for the purpose of reliability monitoring, and its potential will be further exploited in this paper. It is based on usage of universal microprocessor controllers Integraf of series $10 \mathrm{X}$, along with specially designed software package. This system provides real time acquisition of measurements for observed civil engineering structures and analysis of received values based on developed mathematical models.
\end{abstract}

Index Terms - Mathematically modeled constructions, Monitoring, Optimization, Reliability of Civil Engineering Structures.

\section{INTRODUCTION}

With the production of low cost sensors with solar charge and ability for wireless communication a new way is opened for designing systems and applications for monitor parameters of structures in many areas of science and particularly in civil engineering. Monitoring of structures and constructions in civil engineering is very important, especially from the aspect of structure stability and reliability. The stability of engineering structures can be changed over time due to functional deficiencies, changes of material and other properties, changes of load level during long time, or by human errors like negligence and improper maintenance. During design of engineering structures and constructions, the quantities important for their reliability and lifetime (load, material properties, geometry, environmental effects etc.) are calculated. Under the influence of various factors during structure's lifetime, the actual values of quantities may differ from those used in design. In some cases these deviations can result in impaired function, shorter life, or even failure of the structure [1].

The available reliability methods used in civil engineering are presented in [2]. Reliability analysis can be performed using iterative procedures, by Monte Carlo simulations or using special sampling techniques. Limit states are the boundaries between safety and failure. As stated in [3] there are three types of limit states: ultimate limit states, serviceability limit states and fatigue. Ultimate limit states are related to the bending capacity, shear capacity and stability, while serviceability limit states (SLS) are related to gradual deterioration, user's comfort or maintenance costs.

Reliability parameters of a structure can be measured in the design stage or during an operation stage. The factor of safety $(\mathrm{FoS})$, as a measure of reliability of a particular design, can be calculated as a ratio of structural capacity (N) to actual applied load (L). The FoS, calculated in this way, is often referred to as a realized factor of safety. There are also the technical FoS, social FoS or design FoS. Having in mind, that variables $\mathrm{N}$ and $\mathrm{L}$, depend on project parameters, one can introduce the technical FoS. If the social dimension of structure is taken into consideration, the social FoS can be introduced. And finally, we there can be a design FoS, as a constant value prescribed by the law, standard, specification, contract or custom to which a structure must conform or exceed. As we can see, the factor of safety should not be taken for granted. It can be a very complex measure, if we look at a different aspect of a structure. Beside the factor of safety, another factor that has influence on structure reliability is structural resistance. If we want to take into consideration dynamic influences on the structure construction we will refer to this factor as a structural resistance effect. In order to ensure structure safety in relation to functional impairment, technological constraints are used, such as maximum deflection angle, slope, vertical acceleration and others. If their limits are exceeded, the structure is likely to be completely abolished from usage or in some cases structure usage is restricted to minimum.

Engineering structures in operation deteriorate gradually due to many effects of the load, environment or human negligence. An accurate prediction of deterioration processes and of the life-time is impossible especially for long-life structures [1]. However, there are certain methods that can be used in order to predict the effect of environmental and human factors on structures. In literature and in practice two methods are used for improvement of structure reliability during operational stage: computer-supported monitoring of load effects, and fuzzy methods for the evaluation of technical condition. Computer supported monitoring is used for simulation and for monitoring of stress parameters. The stability of construction and its parts, can be monitored using specially designed mathematical model. This model mostly incorporates the following structure parameters: deformations, stretching and structural resistance. On the 
basis of characteristic and measured values, conclusions can be made about structure state. On the other hand fuzzy methods are used for condition evaluation and prediction of structure behavior. Fuzzy logic model matches the relationship between input and output parameters based on the given probability theorem. There are two main parts of the fuzzy logic process input and output membership functions, whose range can be manually defined to fit with input/output logics, and fuzzy rules which are designed by a programmer according to their expertise on solving particular problems [4].

The best solution for structures reliability monitoring would be a combination of the two approaches - a computer system capable of monitoring given structure parameters, simulation of human and environmental factors, prediction of structure behavior and giving recommendations for structure improvements during operational stage. Such computer systems can be applied for river water quality monitoring [5], plant production monitoring [6], or civil engineering structures monitoring [7].

In this paper we will present an architecture of a computer based system designed for Civil Engineering Structures Reliability Monitoring (CERM). The overall objective of CERM is to ensure the stability and reliability of observed structures trough precise measurements and risk assessment using prediction models and expert knowledge. The CERM system is designed to calculate structure parameters in real time, such as deformations, stretching and structural resistance. From calculated parameters, system can predict the behaviour of structure for the given period of time. The software package for CERM system, which is still under development, will be tested in laboratory conditions for measuring certain parameters on models with a goal of optimisation of dynamic influences and stability of structures and constructions. Along with monitoring of structure parameters, system is designed to analyze mathematical model of structure, which is a projection of constructional set and characteristic parts of structure itself, in order to establish a correlation between them. System can be used in the design phase of building, as well as during operation phase, since it can predict behaviour of building and simulate influence of dynamic parameters of environment. In this way it can help calculating the stability of design for the planned lifetime of structure.

\section{CERM SYSTEM ARCHITECTURE}

Architecture of the CERM system for monitoring reliability of structures and constructions in civil engineering is presented in Fig. 1. CERM has a clientserver architecture. Client is used for collection of structure parameters, using different types of sensors. Server is used for gathering measurements from clients and structure and reliability analysis using specialized software. Application software for CERM client and server, along with specially developed communication software makes a unique software package of CERM system for gathering, processing and data supervision on purpose of automatization and increase of structures reliability.

\section{A. CERM client}

Client of the CERM system is installed at the monitored structure's location or on the civil engineering structure itself.

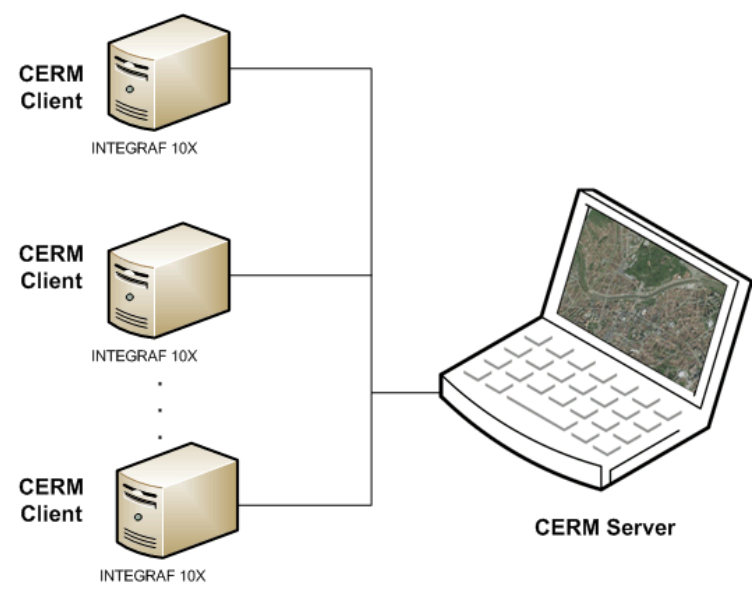

Figure 1. CERM system architecture

It is composed of a universal regulator INTEGRAF $10 \mathrm{X}$ based on microcontroller Philips 80C552 [5]. INTEGRAF 10X (Fig. 2) as a compact universal regulator pro-vides acquisition, regulation, governing, automatization of processes and production systems, supervision and control. It is a high performance microcontroller suitable for instrumentation, industrial governing, automatization of industrial, waterworks or agricultural equipment. Integraf $10 \mathrm{X}$ has eight analog and eight digital inputs which are used for bringing two types of signals (analog and digital) from sensors or other measuring devices. Integraf $10 \mathrm{X}$ software is capable of processing and scaling received technical values of input signals using built in algorithms. On the basis of processed values, controller can administer outputs independently, without human intervention. Integraf $10 \mathrm{X}$ is in a real time connection with CERM clients. The connection can be established using GPRS modem, Ethernet cable, 485 communication interface or PLC.

\section{B. CERM server}

CERM server is in a real time connection with clients, ensuring in that way monitoring of measuring values, distant assigning and accessing structure's parameters. Application software of the CERM server is used for gathering and processing data received from microprocessor controller Integraf 10X (client). Software has the following functions:

- gathering and storing measured values of structure's parameters,

- statistical evaluation of the structures reliability,

- assurance of the quality of the measurements,

- governing of structures using developed algorithms,

- performing prediction of structure behavior based on measured parameters,

- sending alerts on user defined criteria,

- providing user with optimization steps based on expert knowledge database. 


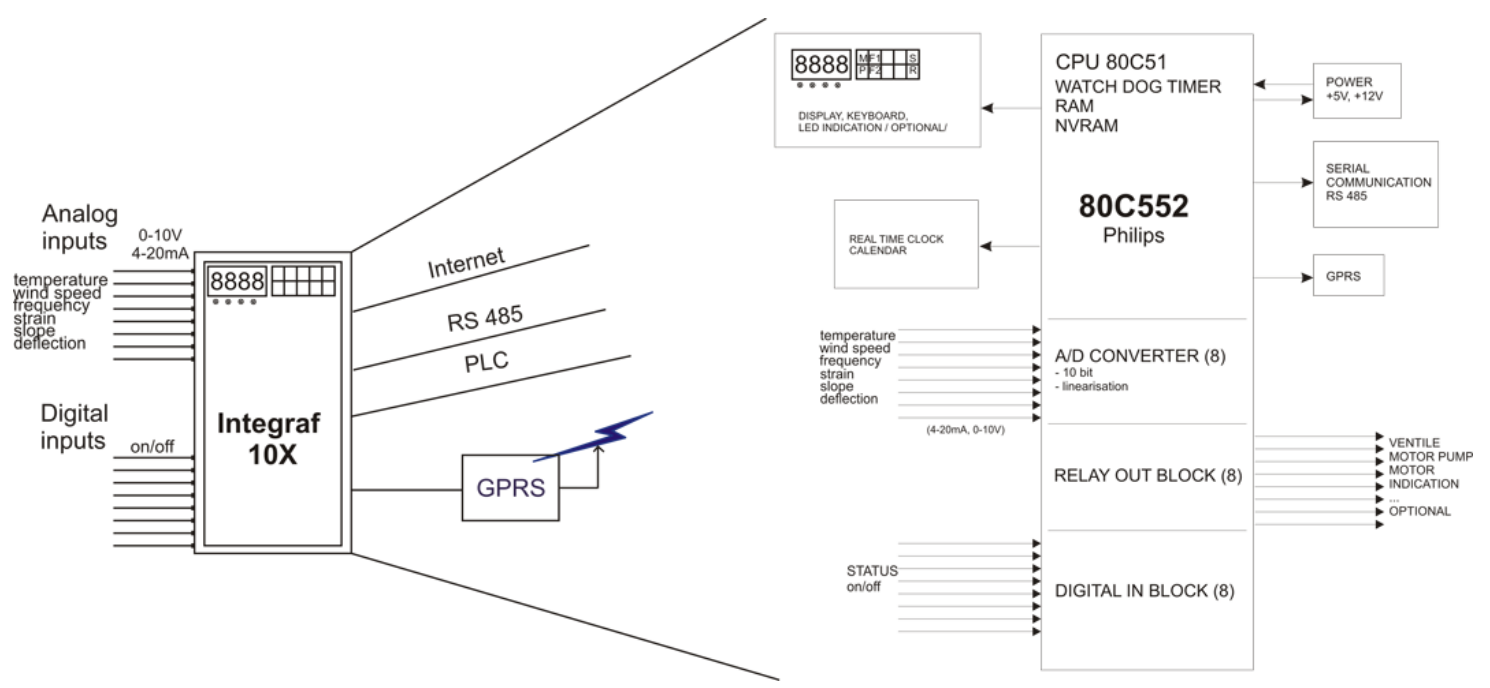

Figure 2. Block schema of CERM client

The software package provides possibility of connecting several systems for tracking and governing, into a single system for central control, automatic regulation and data acquisition

\section{COMMUNICATION SYSTEM}

Communication infrastructure of CERM system is realized using different types of connections. Connection based on GPRS modem, solves the problem of communication between the central computer (server) and microprocessor regulators INTEGRAF 10X (clients) within any area covered with the local mobile network. In system where GPRS modems are used, it is necessary to enable data buffering as a mean of prevention of data loss in cases when there is a traffic blockage or an ability to ensure constant connection. This is why the client of the CERM system, has a buffering function, which ensures that data is secure in cases of technical errors. Although the usage of GPRS assures great flexibility of system in sense of eased expansion of network or excluding of some parts from the existing network, there are some disadvantages in using in comparison to cable connections. First one is the functional dependence of CERM system from the quality of mobile service which depends on the chosen local operator of digital GSM network. The response time is also longer using GPRS modems in comparison to wire connection. The load of the mobile network, often has a significant influence on the response time.

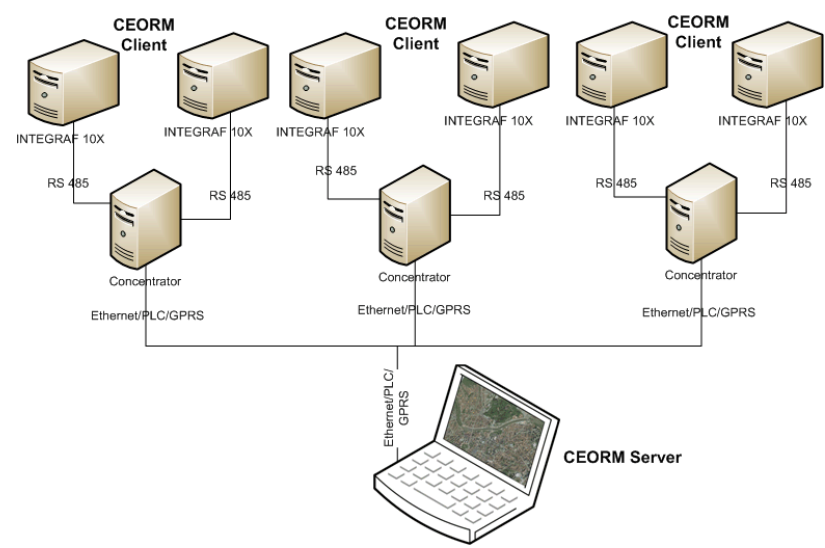

Figure 3. Communication in CERM system
Unreliability of the GSM service provider and the often traffic blockage could give negative reflection on the work reliability of CERM system. These disadvantages have caused the provision of three more types of connection in the CERM real-time system. We have given the client a possibility of using GPRS modems, Ethernet cable, RS 485 communication interfaces or PLC in order to connect to the server component of the system. The CERM system allows connection to several measuring points on one or more structures, and in that way creates a single information system for conjoint control of structures reliability (Fig. 3).

\section{CERM SYSTEM IMPLEMENTATION}

CERM system can be applied for measuring reliability of different types of structures and constructions. Furthermore, it can serve as a central information system for conjoint control of structure reliability on different locations and of different types (Figure 4). In CERM system reliability is calculated on the basis of received and processed values of different structure parameters. Measured structure's parameters can vary depending on structure type (e.g. bridge, roof construction, etc.). Common parameters of interest are mostly strain and temperature, since their changes during structure operation have the fastest effect on structure reliability. For measuring this parameters, resistant strain gauges and thermoelectrical sensors can be attached to Integraf $10 \mathrm{X}$ device. CERM system software will compare measured parameters in real time with the corresponding parameters from the structure's design phase or from measurements' database. If there is a mismatch in values, or if the measured parameters are beyond normal limits, system will suggest optimized constructive changes that should be done on structures, in order to bring the parameters within the limits which indicate structure's safety. CERM system uses equations and expert knowledge in order to calculate current structure reliability or predict future structure behavior. Reliability analysis provides accurate estimate of the current strength and the remaining life time. System can define an optimal strategy for structure optimization, in order to contain structure reliability within the normal ranges. Since the CERM system is in development, before deployment it will be tested for bridges and roof constructions in the laboratory conditions. 


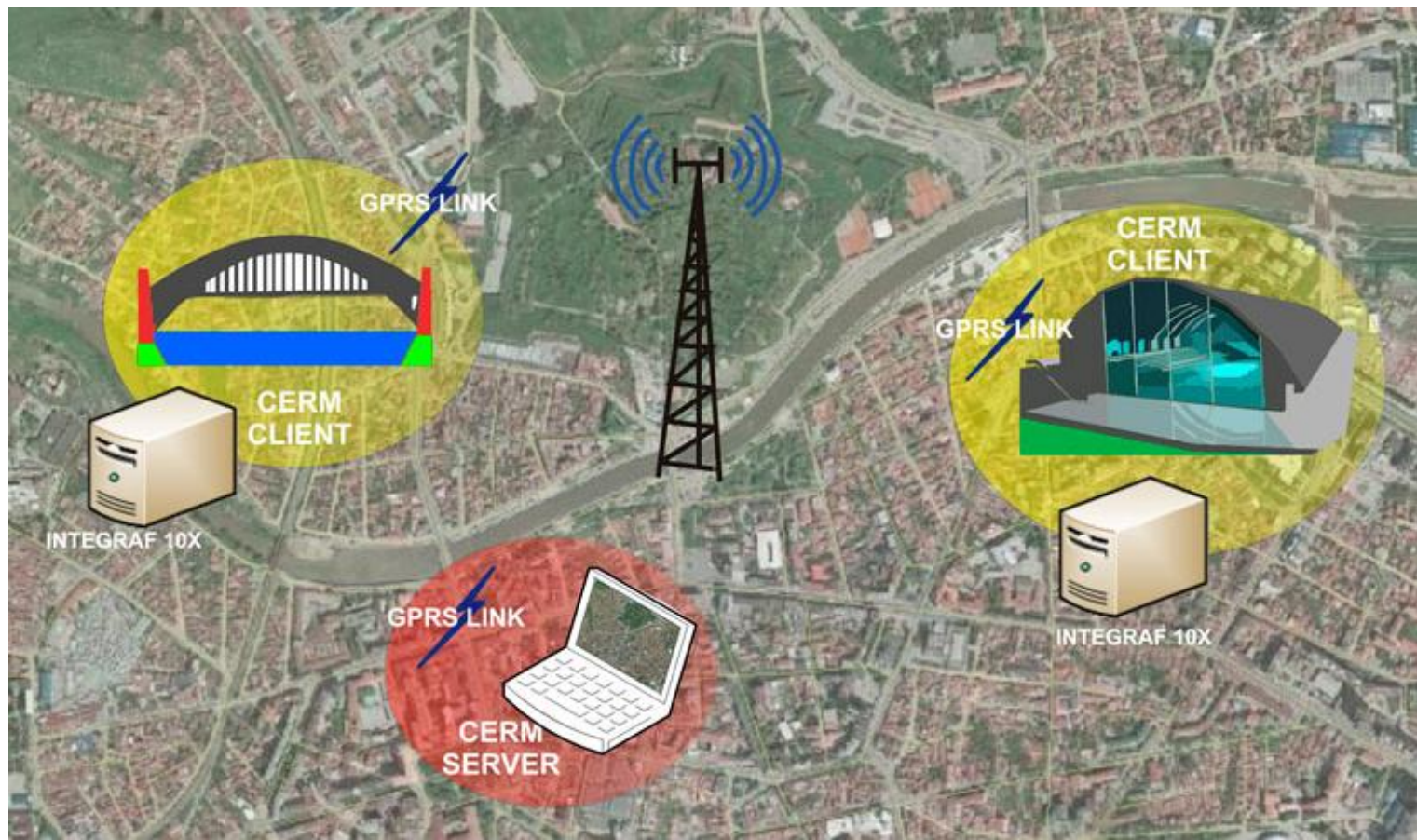

Figure 4. CERM as a central information system

Testing will include the following steps:

1. definition of real structures' mathematical model

2. definition of characteristic structure response for the given parameter value

3. definition of rules for processing the input variables

4. definition of rules for structure reliability optimization

For testing purposes mathematical models of bridge and roof constructions will be defined and entered in the software. For monitoring these two civil structures' reliability, following parameters will be used: temperature, wind speed, frequency, strain, slope and deflection. Simulated input parameters' values will be brought on Integraf $10 \mathrm{X}$ inputs, and forwarded to the server for testing structure reliability for defined mathematical models. If calculated reliability differs from nominal value, system will alert user. Special rules will be defined so that the system could provide user with reliability optimization steps, when there is deviation from the nominal value. Test results of reliability calculation and structure behavior prediction will be judged before CERM appliance for real structures reliability measurements.

\section{CONCLUSION}

Within the last few years, evaluation and reduction of risk has become an important area of research in civil engineering. When structure properties differ from its nominal values reliability, safety and performance are at risk. In order to maintain structure reliability continuous monitoring of structure is necessary. This includes measuring important parameters of civil engineering structures and tracking changes in the construction or material. All this is necessary for an efficient and timely maintenance of structures. Nowadays, there are many methods for monitoring of structures' reliability, but most efficient ones are computer based methods.
In this paper we gave a brief overview of a computer based system for civil engineering structures reliability monitoring (CERM). System is designed to propose necessary steps in order to minimize deviation of characteristic values of measured parameters, which should be within the limits of pre-designed value.

Our future work will include optimization of the system based on laboratory testing and its deployment in real life. Furthermore, we will constantly work to improve developed mathematical models, procedures and algorithms for optimal resolution of problems in the field of civil engineering and architecture. We will try to incorporate the following functions into the CERM system:

- Measuring thermal inertia and energy efficiency of constructions;

- Measuring dynamical characteristics of constructions which implies measurement and acquisition of data during influence of mobile and seismic load and monitoring inelastic deformations and fractures in characteristic cross-sections and points

- Optimization of mathematical models

- Monitoring of construction, materials and real-time impact

\section{REFERENCES}

[1] J. Menčík, "Efficient Tools for Managing Uncertainties in Design and Operation of Engineering Structures," World Academy of Science, Engineering and Technology, vol. 62, pp.409-414, 2010.

[2] A. S. Nowak and K. R. Collins, Reliability of Structures, McGraw Hill, Boston, 2000.

[3] A. S. Nowak, "System reliability models for bridge structures," Bulletin of the Polish Academy of Sciences: Technical Sciences, vol.52, no. 4, pp. 321-328, 2004.

[4] P. Pongpaibool, P. Tangamchit and K. Noodwong, "Evaluation of Road Traffic Congestion Using Fuzzy Techniques," in Proceeding of the IEEE TENCON Conference, Taipei, Taiwan, October 2007. 
[5] N. Marković, J. Džunić, Đ. Đorđević and G. Gruber "Design of a system for central monitoring, control, automatic regulation and data acquisition for ARWQM," Facta universitatis, Series: Architecture and Civil Engineering, vol. 5, no. 2, pp. 95-105, 2007.

[6] T.S. Igic, D.T. Turnic and N.Z. Markovic, "Design of a system for control, monitoring, regulation and data acquisition on civil engineering objects, constructions and mobile modules," in Proceedings of the $7^{\text {th }}$ EUROMECH Solid Mechanics Conference J. Ambrósio et.al. (eds.) Lisbon, Portugal, September 7-11, 2009.

[7] D. Turnic, D. Drenic and T. Igic, Project of Sport Hall in Blace, University of Niš, Faculty of Civil Engineering and Architecture, 2006.

\section{AUTHORS}

T.S. Igić is with University of Niš, Faculty of Civil Engineering and Architecture, Serbia. He is the Department Shairman of Technical Mechanics and Theory of Structures. (e-mail: tomislav.igic@gaf.ni.ac.rs).

N. ̌̌. Veljković is with University of Niš Faculty of Electronic Engineering, Serbia. She is with the Department of Computer Science. (e-mail: natasa.veljkovic@elfak.ni.ac.rs)

Received, April $12^{\text {th }}, 2011$. Published as resubmitted by the authors June $16^{\text {th }}, 2011$. 